\title{
Objetos, Ações e Processos Naturais: de Marcadores Espaço-Temporais à Memórias Socioambientais ${ }^{1}$
}

\author{
Sérgio Almeida Loiola ${ }^{2}$ \\ Sandra de Fátima Oliveira ${ }^{3}$ \\ Alecsandro J. P. Ratts ${ }^{4}$ \\ "O tempo é uma criança que brinca, \\ movendo as pedras do jogo para lá e para \\ cá, governo de criança." 5
}

RESUMO: Este trabalho busca dar continuidade à elaboração de uma perspectiva complexa na geografia. Pressupondo o espaço-tempo socioambiental um co-produto do holomovimento criativo da natureza (LOIOLA, 2010, p.12), argumenta-se que objetos, ações e processos naturais inscrevem marcas materiais e imateriais, convertendo-se em expressões potencias de memórias socioambientais. Ao interagir recursiva e retroativamente com o acontecer presente, as marcas pretéritas não o determinam, porém, orientam a materialização de possibilidades em novas realidades. Tal conversão é evidenciada aqui no uso de marcadores espaço-temporais por sociedades modernas e tradicionais, como resultante de acúmulos de saberes histórico-sociais, extraídos de regularidades celestiais, ciclos ambientais, sociais ou mitos.

PalaVRas-ChaVe: Espaço-tempo; socioambiental; memória; marcadores espaço-temporais.

\section{Objects, Actions and Natural Processes: from spatiotemporal markers for the social- environmental memories}

ABSTRACT: This work represents the continuity of the elaboration of a complex perspective in the geography. Presupposing the space-time socio-environmental a co-product of the holomovement creative of the nature (LOIOLA, 2009: 15), it argues that objects, actions and natural processes inscribe material and immaterial marks, converting itself in potentials expressions of memories social-environmental. As soon as interacts recursive and retroactively with the present, marks of the past don't determine it, however, they orient the materialization of possibilities in new realities. Such conversion is evidenced here through of the use of spatiotemporal markers by modern and traditional societies, resultant of accumulation of historical and social knowledge, extracted of celestial regularities, environmental, social cycles and of the myths.

KEY WORD: space-time socio-environmental; memory; spatiotemporal markers.

\footnotetext{
${ }^{1}$ Elaborado a partir da dissertação de mestrado, defendida em 2008, junto ao IESA - UFG, sob o título: Por uma geografia do passado distante: marcas pretéritas na paisagem como memória espacial das sociedades autóctones.

2 Doutorando em geografia - UFG: Paleoclima e Sociedade. Integrante do NUPEAT- Núcleo Pesquisas em Educação Ambiental e Transdisciplinaridade, IESA, UFG. sergioaloiola@gmail.com

${ }^{3}$ Profa Dra pesquisadora em ciências ambientais junto ao IESA, UFG. Coordenadora do NUPEAT-IESA -UFG. sanfaoli@iesa.ufg.br

${ }^{4}$ Prof. Dr. pesquisador em geografia e antropologia junto ao IESA, UFG. Coordenador do NEAAD/UFG - Núcleo de Estudos Africanos e Afrodescendentes, e do LaGente - Laboratório de estudos de Gênero, étnicos-raciais e espacialidades. alex.ratts@uol.com.br

${ }^{5}$ Heráclito de Éfeso (540 a.C. $-\underline{470}$ a.C.).
} 


\section{INTRODUÇÃO}

No processo de realização geográfica das formações socioespaciais, marcas são inscritas nas paisagens, na memória e interferem nas ações atuais, de modo que a compreensão da dinâmica socioambiental impõe tratar simultaneamente o presente e as heranças do passado, sobretudo as implicações dessa interação.

Ontem e hoje se coadunam produzindo o espaço-tempo socioambiental numa teia recursiva e retroativa, cuja única constante da complexa polimorfia é a mudança, não-linearidade e a instabilidade (LOIOLA, 2010, p. 15-16). Nesse perpétuo movimento, eventos geográficos derivam de um imbricado sistemas de objetos, ações e processos naturais, compostos de objetos fabricados e não fabricados, herdados e criados, contínuos e descontínuos, reais e imaginários.

Desta forma, eventos inscrevem marcas no espaço-tempo socioambiental. Dos sucessivos acúmulos resultam rugosidades plenas de marcadores potencialmente manifestos, sempre à espera de novos significados, seja nos aspectos físicos, biológicos, informações, cultura material ou a memória dos povos. Se essas heranças influenciam o processo de realização geográfica é porque há uma conversão dos marcadores espaço-temporais em atributos de memórias socioambientais. É o que será tratado, a partir das especificidades dos marcadores espaço-temporais utilizados por sociedades modernas e tradicionais.

\section{PRODUÇÃo E SIGNIFICADOS DAS RUGOSIDADES DO ESPAÇO-TEMPO SOCIOAMBIENTAL}

Por ser lugar da escrita da história, o espaço é marcado por processos vividos em diferentes momentos (SANTOS, 1997: 66-68). As sociedades, inseridas nos processos naturais e movidas por intencionalidades, historicamente se tornaram sedentárias e se complexificaram. Por meio do trabalho e das técnicas elaboraram artefatos e construções, registrados nos objetos da paisagem, nas alterações ambientais, nas informações e na memória dos povos.

Resultantes da experiência humana na Terra, essas marcas exprimem relações com o ambiente para atender suas necessidades, gostos e aspirações (SANTOS, 1996: 112). No processo de realização geográfica as sociedades adquirem crescente consciência de integrarem o ambiente e agirem sobre os signos de hoje e do passado (SANTOS, 2004, p.60). 
Os acúmulos diferenciais das sucessivas marcas dos momentos vividos informam as rugosidades no espaço, pré-condição ao acontecer, ou à projeção do futuro (SANTOS, 1996: 112). Num sentido, a rugosidade é um lastro inercial da dinâmica socioambiental, já que é a lembrança do que se passou interferindo no presente. Noutro, por trás dessa aparente inércia fluem novos eventos no movimento criativo da natureza, denotando que nada está estático, tudo é relacional e dinâmico (MORIN \& LE MOIGNE, 2000: 34).

Eventos representam, assim, o movimento ininterrupto de criação da realidade. São a contínua geração do novo a partir de infinitas possibilidades contidas no todo (GOSWAMI, 2001: 175). Materializam acontecimentos singulares entre tantos possíveis, cujas marcas permitem diferenciar os momentos nas sociedades e nos ambientes, sejam no campo das idéias, processos, fatos ou fenômenos. Suas marcas informam um lugar no espaço e no tempo do acontecer, tornando-se parcelas espaço-temporais singulares da e na realidade.

O espaço-tempo socioambiental é assim uma sucessiva integração de processos naturais, sistemas de objetos e ações, cujas formas, estruturas e significados interagem com o presente. Espaço e tempo não só nascem juntos, mas, para além de instância social, comportam-se como atributo da natureza, sendo interdependentes e indissociáveis do seu holomovimento universal criativo e perpétuo (LOIOLA, 2009: 6).

"Mas o resultado real deste argumento é que o tempo precisa do espaço para ele mesmo avançar; tempo e espaço nasceram juntos, junto com a relação que os produz. Tempo e espaço tem que ser pensados juntos, pois eles estão inextricavelmente entrelaçados." (MASSEY, 1999: 274) ${ }^{6}$

Intrínsecas ao acontecer no presente, as marcas na paisagem, a memória, as informações e a cultura material são elementos da multidimensionalidade do espaço-tempo socioambiental, não o determinam, mas promovem interações não-lineares de sucessões diacrônicas, coexistências sincrônicas e interações anacrônicas, de acordo com os diferentes níveis de realidade (LOIOLA, 2009: 9).

"Neste caso, a primeira implicação deste ímpeto de considerar a temporalidade/história como genuinamente aberta é que espacialidade tem que ser integrada como uma parte essencial deste processo da 'contínua criação de novidade." (MASSEY, 1999: 274)

\footnotetext{
6 "But the real result of that argument is that time needs space to get itself going; time and space are born together, along with the relations that produce them both. Time and space must be thought together, therefore, for they are inextricably inter-mixed. A first implication, then, of this impetus to envisage temporality/history as genuinely open is that spatiality must be integrated as an essential part of that process of 'the continuous creation of novelty'."
} 
A percepção dos resíduos desse espaço-tempo socioambiental requer olhares que ultrapassem estruturas, formas, processos e ações presentes. Ver além das formas herdadas é buscar significados na memória, nas informações, sondagens indiretas e elementos imateriais, entendidos como marcadores espaço-temporais, argumentos potenciais de memórias socioambientais.

\section{DOS MARCADORES ESPAÇO-TEMPORAIS ÀS MEMORIAS SOCIOAMBIENTAIS}

Heranças resultantes de processos socioambientais e naturais portam signos construídos e relativamente autônomos, mas que conservam sintonia com o modo de pensar e agir de um povo. Sua análise gera conteúdos interpretativos úteis às sociedades atuais. Denotam maneiras dos povos se relacionarem com o ambiente, entre si e a sua estruturação (LOIOLA, 2010 p. 8-9).

A partir das formas pretéritas, das informações, marcas resultantes de processos, da memória e as alterações impressas na paisagem heranças adquirem relevância, sentido e novos significados ante as leituras do presente (SANTOS, 1997: 68). Tanto os aspectos materiais quanto os imateriais herdados se tornam matriz cultural, transmitem significações de uma geração a outra (BERQUE, 2004: 84).

Assim, marcadores espaço-temporais convertem-se em memórias socioambientais, dão suporte às representações sociais e promovem as identificações étnicas e culturais (LOIOLA, 2010, p. 11-12). De modo que, a produção do espaço-tempo socioambiental deriva de um entrelaçamento histórico, social, ambiental e cultural, diferindo de acordo com as condições naturais, referenciais adotados e os significados atribuídos às heranças do passado.

Noções acerca do espaço e do tempo são formadas a partir de processos histórico-sociais, apresentando-se conforme o simbolismo de cada cultura (BORGES, 2006: 40). Geralmente, tais noções correspondem a referenciais celestiais e ambientais, resultantes de processos contínuos de aprendizagem e acúmulo de saberes, associados à forma de estruturação social, destinados à orientação, regular ciclos e ritmos sociais visando a perpetuação, o que denota a indissociabilidade socioambiental.

Perceber essa profusão de noções de tempo-espaço em outras sociedades é difícil tarefa, pois os padrões conceituais sobre o tempo e espaço na civilização ocidental estão tão 
arraigados que tendem a obscurecer como outros povos viveram e vivem sem o tempo cronológico, o relógio e a geometria euclidiana (ELIAS, 1998: 32).

Notadamente, a técnica é o meio predominante para perceber/conceber marcadores contidos no entrelaçamento espaço-tempo. Uma vez que o espaço tem componentes materiais e empíricos, é possível empiricizar o tempo, dado o espaço conter registros dos sucessivos eventos. A técnica permite às sociedades realizarem a mensuração do tempo imerso no espaço, já que é um meio constitutivo do espaço e do tempo, tanto no campo operacional quanto percebido, ou subjetivo (SANTOS, 1996: 44).

A técnica é um recurso que evidencia a indissociabilidade espaço-tempo, pois entra como um traço de união, histórica e epistemologicamente. De um lado, possibilita empiricizar o tempo, de outro, permite qualificar as heranças do passado (SANTOS, 1996: 44).

Nessa perspectiva, é possível distinguir dois conjuntos peculiares de conceber os marcos espaço-temporais e interagir com as heranças do passado (ELIAS, 1998: 32). Um caracteriza as sociedades ocidentalizadas, envolvendo tecnologias associadas ao uso de um meio técnico científico informacional. No outro predominam ciclos e ritmos naturais, signos mitológicos e técnicas simples, empregados por sociedades tradicionais.

\section{MARCADORES ESPAÇO-TEMPORAIS NAS SOCIEDADES OCIDENTAIS}

Compreender os significados das heranças do passado é tarefa complexa, de crescente interesse no mundo ocidentalizado. Marcas residuais expressam memórias socioambientais, seja na mitologia ou nos ritos, nos ciclos ambientais, nas formas pretéritas, ou nos movimentos celestiais. Suas regularidades descrevem marcadores potenciais num todo relacional de fenômenos multidimensionais. Suas perspectivas ultrapassam fronteiras disciplinares, exigindo apreensão multirreferencial.

Na geografia a paisagem é lócus privilegiado por ser guardiã de processos pretéritos e síntese de potencialidades manifestas. Além de imagem co-produzida pelos sentidos (COSGROVE, 1998: 99), a paisagem conserva uma ontologia em movimento. Nela, processos físico-biológicos e a sociedade ininterruptamente agem e a transformam, materializando desejos e aspirações decorrentes do trabalho e das técnicas.

Nenhuma sociedade prescinde dos signos e materialidade da paisagem na realização cotidiana. Vias férreas, aeroportos e estradas orientam rotas; redes elétricas, de esgoto, 
aquedutos e redes de telecomunicações informam a distribuição e a interligação dos sistemas; uma divisão social do trabalho e do poder encontra-se exposta na diferenciação espacial dos lugares de moradia, produção, distribuição e centros de decisão.

Juntamente com a memória, a paisagem torna-se guardiã das sucessivas marcas socioambientais inscritas no espaço-tempo: "O seu traço comum é ser a combinação de objetos naturais e de objetos fabricados, isto é, objetos sociais, e ser resultado da acumulação da atividade de muitas gerações." (SANTOS, 2004: 53).

A paisagem adquire uma forma ambivalente e complementar socioambiental, dotada de historicidade (BERQUE, 2004: 84; WORSTER, 1991: 202; FREITAS, 2003: 7). Nela, vestígios dos eventos pretéritos permitem especular seus simbolismos, tornando-a lembrança do passado sob um conjunto de significados espaços-temporais. Quando indagadas, suas sucessivas marcas revelam as práticas espaciais pretéritas, possibilitando realizar interpretações geográficas do passado ao identificar a função dos elementos, sua estrutura, e o imbricado de processos socioambientais e naturais (LOIOLA, 2008: 84; 2007: 276).

Para a geografia, a arquitetura das cidades, aldeias, casas, vias e redes de transportes, a distribuição espacial, ferramentas, vestígios de uso do solo, alterações ecológicas, uso da energia e todo tipo de sinal de atitudes específicas demonstram as técnicas e os instrumentos do seu sistema de engenharia; revelam a estrutura espacial: seus sistemas de referência, rotas, fluxos, práticas espaciais, redes, hierarquias, territórios, aspectos comportamentais permitem compreender seu modo de produzir, organizar e se proteger (CLAVAL, 1997: 103; SANTOS, 1997: 67; GOMES, 1998: 31; LOIOLA, 2008: 84).

$\mathrm{Na}$ arqueologia, marcadores espaço-temporais informam o período aproximado dos vestígios de sociedades pretéritas, seus modos de vida, estruturas sociopolíticas e possibilitam reconstituir paleoambientes e paleoclimas. Cronologias relativas são extraídas por decapagem e estratigrafia, permitindo separar níveis de sedimentos deposicionados, correlatos a duração aproximada dos paleoclimas (PROUS, 2006: 13-17).

Marcadores de maior regularidade assumem valor de relógios de tempo. Na civilização ocidental há uma macro e uma micro-cronologia, mensuradas em geral pela astronomia e pela física. Na macro-cronologia predomina o tempo mensurado fundamentado em observações astronômicas das estrelas, pulsares, quasares etc., da mecânica celeste, rotação 
da Terra e seu fracionamento em unidades menores, como o Ano luz e o Parcec. ${ }^{7}$ Na microcronologia a unidade singular é o segundo e suas frações, obtido sob métodos de datação absoluta referenciado em emissões (decaimento) de partículas de materiais radioativos, denominados relógios atômicos.

Entre as técnicas mais utilizadas na datação absoluta estão as de radiocarbono e termoluminescência (PROUS, 2006: 15). A primeira é realizada a partir da radioatividade residual do carbono 14 preservado em carvões vegetais de fogueiras construídas por grupos humanos, ossos e conchas, alcançando datações de até 40 mil anos AP (Antes do Presente). A datação por termoluminescência residual de partículas de sílica queimada em cerâmicas e instrumentos de sílex possibilita datar períodos mais recuados do que 40 mil anos AP, assim como as partículas radioativas de urânio e tório, empregadas na datação de ossos.

Aspectos específicos nas marcas espaço-temporais informam detalhes dos hábitos alimentares, esforço físico, patologias, características da população e técnicas usadas no passado. Há que se observar tanto dados qualitativos quanto quantitativos, já que não se pode conhecer a dieta de um grupo simplesmente associando-a aos utensílios (ALBUQUERQUE, 1989: 64-65).

A dieta e consumo de cada alimento é revelada na análise química dos ossos, das cáries, abrasão dentária e doenças resultantes da dieta alimentar, esforços repetitivos e hábitos. A procedência geográfica dos alimentos pode ser especulada nessa análise, pois alguns isótopos estáveis são incorporados aos tecidos dos indivíduos que os consumiu, e em proporções compatíveis com a espécie e a quantidade do alimento ingerido (ALBUQUERQUE, 1989: 65).

De forma análoga, bioquímicos identificam parasitas intestinais nos coprólitos (fezes fossilizadas) e alimentos da dieta (ARAÚJO \& FERREIRA, 1997: 58). Algumas técnicas consistem em verificar a relação entre o Carbono 12 e seu isótopo estável 13; o Nitrogênio 15 e o isótopo estável 16; e o uso do estrôncio, que por ser mais abundante em plantas que animais, fornecem as proporções de vegetais e animais na dieta.

Restos esqueletais são avaliados por bioantropólogos a fim de verificar o sexo, idade, características físicas da população e, com auxílio de paleogeneticistas, fazem estudos com o

\footnotetext{
${ }^{7}$ Parsec: unidade de distância astronômica. É a distância de um objeto cuja paralaxe anual média é um segundo de arco (1"). Ou, a distância à qual deveria se situar um observador para ver a distância entre a Terra e o Sol sob o ângulo de um segundo de arco. Ano luz: distância percorrida na velocidade da luz durante um ano (FARIA, 1987).
} 
RNAt ou DNA mitocondrial e traçam a filogenia, ancestralidade e a linhagem evolutiva, bem como possíveis origens geográficas (PROUS, 1999: 24). Paleoantropólogos avaliam a demografia a partir da quantidade e características dos esqueletos encontrados em cemitérios, inferem os esforços físicos, posturas do corpo e distribuição populacional, divisão sexual do trabalho e comportamentos.

Tão importante quanto encontrar instrumentos fabricados é identificar a cadeia operatória: as matérias primas, sua origem, as técnicas de confecção, quantidade produzida, trocas e/ou comércio. Isso é possível na análise petrográfica da rocha que, ao indicar o local de retirado do material, revela as relações de trocas e/ou a mobilidade populacional (PROUS, 1999: 24). Dados similares são obtidos na análise química por ativação neutrônica dos minerais que compõem as argilas usadas na manufatura de cerâmica, por exemplo.

As técnicas empregadas na manufatura são desvendadas na análise microscópica, as quais informam as marcas devido ao uso repetitivo, os materiais e o tipo de trabalho associado (FOGAÇA e BOEDA, 2006: 674-675). Com essas informações, as ferramentas são reproduzidas e testadas a fim de comprovar as técnicas, as especificidades na produção e em toda cadeia operatória.

Uma gama infindável de especialidades e métodos participam na obtenção dos marcadores espaço-temporais. O clima é tratado por paleoclimatólogos e palinólogos; a paisagem, o solo, o relevo, a geologia e a hidrografia, são objeto de geomorfólogos, geólogos e pedólogos; espécies vegetais e animais e seu históricos por biogeógrafos, paleobotânicos e paleontólogos; e o estudo dos pólens é realizado por palinólogos (ALBUQUERQUE, 1989: 6571).

Nesse conjunto, a técnica representa a mediação espaço-temporal. Ao revelar marcadores, permite propor um quadro cotidiano dos grupos e suas interações com o ambiente, a partir de métodos, técnicas e teorias à disposição no momento. Entretanto, na arqueologia e seguramente nas demais disciplinas, o uso de metodologias duras de investigação do passado não torna as conclusões nem mais nem menos definitivas do que as dos historiadores e refletem não a realidade do passado, mas a visão que deles podemos conseguir hoje (PROUS, 1999: 27).

Importa perceber que os significados atribuídos às heranças do passado, materiais ou imateriais, assumem cada vez mais relevância ao mundo moderno. Embora não determinem 
- acontecer presente, signos herdados são sua pré-condição, ampliam o leque de possibilidades e retroagem na materialização de novas realidades.

\section{MARCADORES ESPAÇO-TEMPORAIS NAS SOCIEDADES TRADICIONAIS}

As escolhas dos marcadores do espaço-tempo nem sempre seguem as representações ocidentais. A formação igualitária dos povos autóctones do Brasil é exemplo da diversidade em lidar com as outras noções de tempo e espaço, cuja base funda-se na observação de marés, cheias cíclicas de rios, períodos de estiagem, chuvas, frutificação e observações do firmamento, associado-as aos seus mitos. ${ }^{8}$

Essas sociedades possuem formas diferenciadas de reproduzir saberes. Sua cultura é transmitida de geração em geração por meio de ritmos, linguagem, ritos, mitos, gravuras, danças rituais, práticas espaciais, arquitetura, técnicas, sinais, pinturas, símbolos, marcas na paisagem, memória, sentimento de pertencimento etc (GUIDON, 2004: 74; WÜST, 1999: 329-330). Seu signos são ainda pouco compreendidos.

"Algumas danças nossas, que algumas pessoas não entendem, talvez achem que a gente esteja pulando, somente reagindo a um ritmo da música, porque não sabem que todos esses gestos estão fundados num sentido imemorial, sagrado. Alguns desses movimentos, coreografias, se você prestar atenção, ele é o movimento que o peixe faz na piracema, ele é o movimento que um bando de araras faz, organizando o vôo, o movimento que o vento faz no espelho da água, girando e espalhando, ele é o movimento que o sol faz no céu, marcando sua jornada no firmamento e é também o caminho das estrelas, em cada uma das suas estações." (Krenak, 1992, p. 202)

Essa memória não é a fotografia estática de um passado como propôs Bérgson já que na maior parte das vezes, lembrar não é reviver, mas refazer, reconstruir, repensar, com imagens e idéias de hoje, as experiências do passado (BOSI, 1987: 17). Estimulada por narrativas míticas, o ambiente e toda sorte de objetos, a memória, coletiva ou individual, são mecanismos não só de representação espaço-temporal, mas igualmente de co-produção do mundo. É parte de um conjunto relacional de reprodução cultural.

\footnotetext{
${ }^{8}$ Formação socioespacial igualitária: caracterizada por domínio territorial e laços de poder horizontalizados tanto na gestão e estruturação quanto na defesa; divisão social do trabalho, modo de produzir e viver voltados à auto-suficiência, base agrária, valores culturais de nãoacumulação; pouca concentração de poder e hierarquia; inexistência de Estado e moeda de troca; predomínio do escambo; flexibilidade e laços socioculturais internos e externos diferentes etnias, línguas e bases econômicas. Ver PROUS (2006), GUIDON (2003; 2005), FUNARI (2002) e LOIOLA (2008).
} 
"Esse jeito de viver que informa a nossa arquitetura, nossa medicina, a nossa arte, as nossas músicas, nossos cantos. Nós não temos uma moda, porque nós não podemos inventar modas. Nós temos tradição, e ela está fincada em uma memória da antiguidade do mundo, quando nós fazemos parentes, irmãos primos, cunhados, da montanha que forma o vale onde estão nossas moradias, nossas vidas, nosso território." (KRENAK, 2001: 202)

Nos seus referenciais espaço-temporais muitas vezes a experiência é associada a uma representação mental da realidade por uma geografia imaginativa, seja ela cognitiva ou performática. No primeiro caso, a representação de base cognitiva ou mental inclui tanto as imagens do ambiente guardadas na mente para encontrar caminhos ou se orientar no espaço, quanto os artefatos físicos que registram modos de perceber o espaço e os lugares (SEEMANN, 2003: 270).

No segundo caso, em que predomina uma cartografia de performance, a representação é expressa por atos não materiais para explicar práticas espaciais: gestos, rituais, canções, processos, danças, poemas e histórias, permitindo o deslocamento e a percepção nos ciclos, ritmos e ritos, sem a construção de instrumentos de mensuração. Há também representação por artefatos físicos fixados em lugares, como os da arte rupestre ou registros móveis portáteis em cerâmica ou tecido, com descrição ou desenhos de performance (SEEMANN, 2003: 270).

Essas representações expressam a profusão de simbolismos espaço-temporais adotados por outras culturas, tão eficaz quanto as formas geométricas euclidianas (SEEMANN, op cit). Essa eficácia é conhecida de longa data no Brasil, onde o conhecimento das etnias locais foi e é explorado desde o período colonial. Nenhuma bandeira prescindia dos seus saberes para adentrar o sertão (TENÒRIO, 1999: 260; ALBUQUERQUE, 1989: 71).

Eram os autóctones que orientavam os caminhos e trilhas; desenhavam símbolos de orientação sobre as rochas nas margens dos rios acerca dos peixes ali existentes; ajudavam na confecção cartográfica, registrando os acidentes geográficos; orientavam a navegação fluvial, conduzindo as embarcações em lugares de melhor navegabilidade nos rios. Localizavam espécies comestíveis e venenosas, medicinais, madeiras boas e os locais seguros para descanso a fim de evitarem ataques de outras etnias, animais silvestres e insetos. Utilizando-se de uma geografia imaginativa, delimitavam cada território empregando signos de um passado longevo, trazido na memória.

"Aqui nesta região do mundo, que a memória mais recente instituiu que se chama América, aqui nesta parte mais restrita, que nós chamamos de Brasil, 
muito antes de ser "América" e muito antes se ter um carimbo de fronteiras que separa os países vizinhos e distantes, nossas famílias grandes já viviam aqui. Essas nossas famílias grandes, que já viviam aqui, são essa gente que hoje é reconhecida como tribos. As nossas tribos. Muito mais do que somos hoje, por que nós tínhamos muitas etnias, muitos grupos com culturas diversas, com territórios distintos. [...] Nos lugares onde cada povo tinha a sua marca cultural, seus domínios, nesses lugares, na tradição da maioria de nossas tribos, de cada um de nossos povos, é que está fundado um registro, uma memória da criação do mundo." (KRENAK, 1992:.201)

Com freqüência a cultura e os conhecimentos das sociedades igualitárias foram subestimados por comparações histórico-lineares. No passado muitos antropólogos e naturalistas descreveram que os povos autóctones no Brasil possuíam pensamento exclusivamente emocional e mítico e não realizavam observações astronômicas nem a marcação do tempo e espaço. No entanto, observações minuciosas atestam que esses povos milenares detêm saberes e história singulares (PROUS, 2006: 126-130; GUIDON, 2004: 7581; FUNARI, 2002: 98-101; WUST, 1999: 321-323).

LÉVI-STRAUSS corrigiu os equívocos e demonstrou que essas sociedades fazem isso por meio de intelectuais, exatamente como um filósofo, ou até mesmo um cientista, pode e faz, após presenciar os boróro no Mato Grosso deitados em esteiras observando as estrelas em 1936 (LÉVI-STRAUSS apud FABIAN, 2006: 61). Por serem atentos observadores celestes, FABIAN (2006) denominou os boróro de "astrônomos do Cerrado".

Os boróro aplicam conhecimentos astronômicos no planejamento da planta de situação das aldeias, na estruturação sócio-espacial, na marcação do calendário de eventos culturais e mitos. De forma objetiva, orientados pelo sol, a lua e a constelação das Plêiades, constroem um calendário rigoroso de coleta, agricultura, pesca e caça, obtendo o máximo do ambiente com baixo impacto ecológico ao garantirem um ciclo de abastecimento com grande fartura anual (FABIAN, 2006: 58).

Os tupi desenvolveram técnicas próprias de marcação dos ciclos celestiais. Em relatos do século XIX o navegador e governador da Capitania de Goiyás, Couto de Magalhães, explica que esse povo divide o dia não em horas, mas em intervalos de duas e três horas, atribuído um nome para cada intervalo, segundo o movimento do sol no céu, da lua e das constelações:

"Os indígenas não dividiam o dia e a noite em horas e sim espaços, mais ou menos, de duas e três horas, a saber: Do nascer do sol até as $9 \mathrm{~h}$ : Coema; Das $9 \mathrm{~h}$ ao meio dia: Coarací iauaté (sol alto); Meio dia: Caie ou iandára; Do meio dia às 5 h: A'ra; Das 5 h às 7 
h: Carúca, Karúca; Das $7 \mathrm{~h}$ à meia noite: Pitúna; Meia noite: Piçaié; Da meia-noite às $4 \mathrm{~h}$ : Pitúma pucú (noite comprida); Das $4 \mathrm{~h}$ às $6 \mathrm{~h}$ : Coema pirãnga (vermelho da manhã, madrugada) e das $6 \mathrm{~h}$ às $9 \mathrm{~h}$ : Coema." (apud LIMA FILHO, 2006: 82)

Existem anotações mais recuadas no tempo que as de Lévi-Strauss e Couto Magalhães. A importância da observação da lua, sol e constelações para os tupi foi registrada pelo missionário CLAUDE D’ABBEVILLE em 1612, ao identificar o nome de trinta constelações e estrelas conhecidas desse povo. Impressionado, Abbeville relatou: "Poucos entre eles desconhecem a maioria dos astros e estrelas de seu hemisfério; chamam-os todos por seus nomes próprios, inventados por seus antepassados" (apud AFONSO, 2006: 48).

Abbeville relatou que os tupi já sabiam do efeito maré provocado pela força de gravidade da lua: "[...] os tupinambás atribuem à Lua o fluxo e o refluxo do mar e distinguem as duas marés cheias que se verificam na lua cheia e na lua nova ou poucos dias depois.", antes mesmo de Galileu Galilei (apud AFONSO, 2006: 51; FIGURA 1)

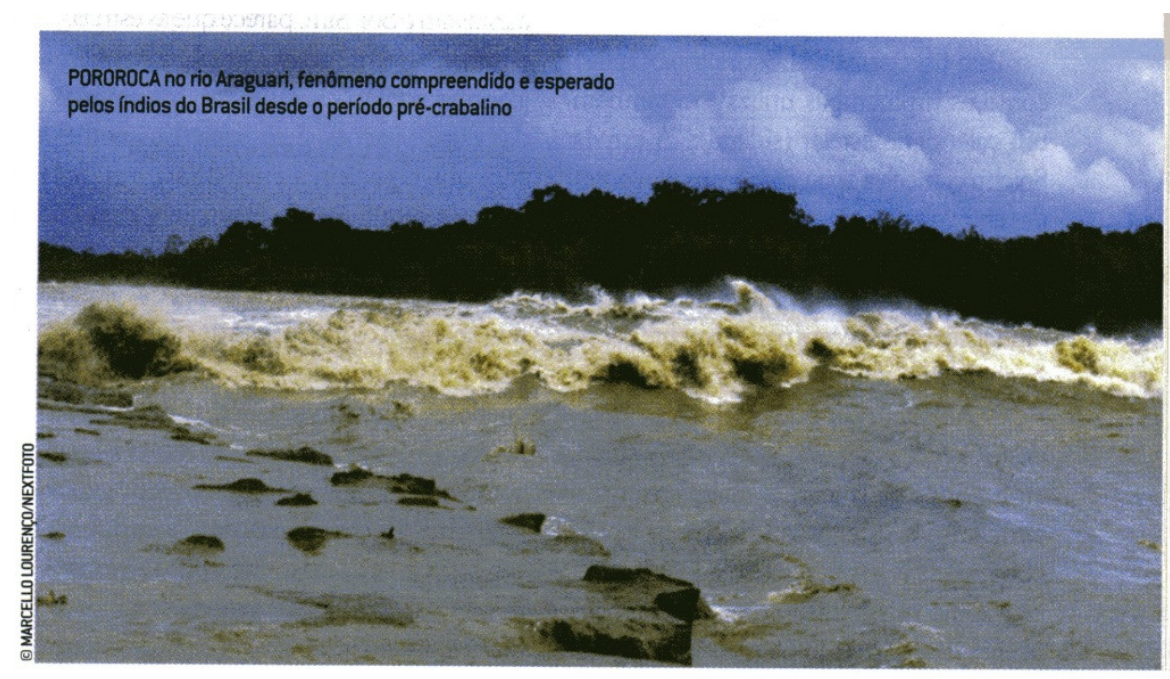

Figura 1: Povos do Brasil já previam a pororóca em grandes rios descreviam e constelações. FONTE: Scientific American, 2006.

Para os tupi-guarani as aparições consecutivas de uma mesma fase da lua determinam o mês. Usando rochas e a determinação dos extremos do movimento do sol nos solstícios e equinócios marcam os quatro pontos cardeais e definem a primavera, verão, outono e inverno (AFONSO, 2006: 50). Seus pontos cardeais são expressos metaforicamente: o norte é para onde o sol é curto, o sul para onde o sol é comprido, o leste de onde o sol vem e o oeste é para onde o sol vai (BORGES, 2006: 45). 
Tanto esses marcadores quanto diversas constelações encontram-se enunciadas no mundo mítico e nas crenças dos tupi-guarani, profundos conhecedores dos movimentos naturais e os reflexos sobre o espaço de vivência.

Conforme descreveu BORGES (2006: 40-45), quando o referencial de marcação temporal segue fenômenos ambientais, os povos autóctones brasileiros em geral dividem as estações do ano em duas: uma seca, para o verão, e outra chuvosa ou a cheia, equivalente ao inverno. Os krahô fazem esse tipo de marcação com duas estações do ano. O calendário wayampi segue um ciclo de início e final de temporadas das frutas, marcado com nomes de animais e frutas.

Outros povos no Brasil têm métodos próprios de marcação espaço-temporal. Os ikpeng, do Xingu, de acordo com Borges (2006: 42), fazem vários nós num fio de algodão para marcar o tempo de duração de uma caçada. Os caiapó utilizam ciclos rituais como marcadores temporais, entre os quais se destaca o meõtõmõr, expedição ritual de caça e iniciação do jovem à fase adulta. Já os guarani constroem o ciclo anual a partir de alterações relacionadas aos ventos de inverno e os ventos novos no período do florescimento da vegetação, incorporando essas temporalidades às suas narrativas míticas.

\section{MEMÓRIAS SÓCIOAMBIENTAIS NA MITOLOGIA INÃ: A DÁDIVA DO ARAGUAIA ${ }^{9}$}

No início do século XXI o Mapa etnohistórico de Curt Nimuendeju ainda é a melhor ilustração da diversidade étnica autóctone que pré-existia na terra brasilis (antes de constituir o que hoje denominamos território brasileiro). Esse mapa permite correlacionar os territórios ocupados por diversas etnias remanescentes, e expõe que a Família Karajá: Karajá, Javaé e Xambioá ocupa as proximidades de seus territórios tradicionais (FIGURA 2).

Enquanto Martius e Spix escreveram com certo desdém sobre os Karajá em "Viagem ao Brasil" (1817-1820): "Nas leis e forças da natureza eles não pensam, e, portanto, não as podem designar com palavras." (apud LIMA FILHO, 2006: 89); José Vieira Couto de Magalhães narrou o oposto em "O selvagem", de 1876, o uso de estrelas e constelações pelos karajá na contagem do tempo, seja para auxiliar a navegação no rio Araguaia, seja para mensurar o tempo transcorrido.

\footnotetext{
${ }^{9}$ Inã é autodeterminação dos karajá.
} 


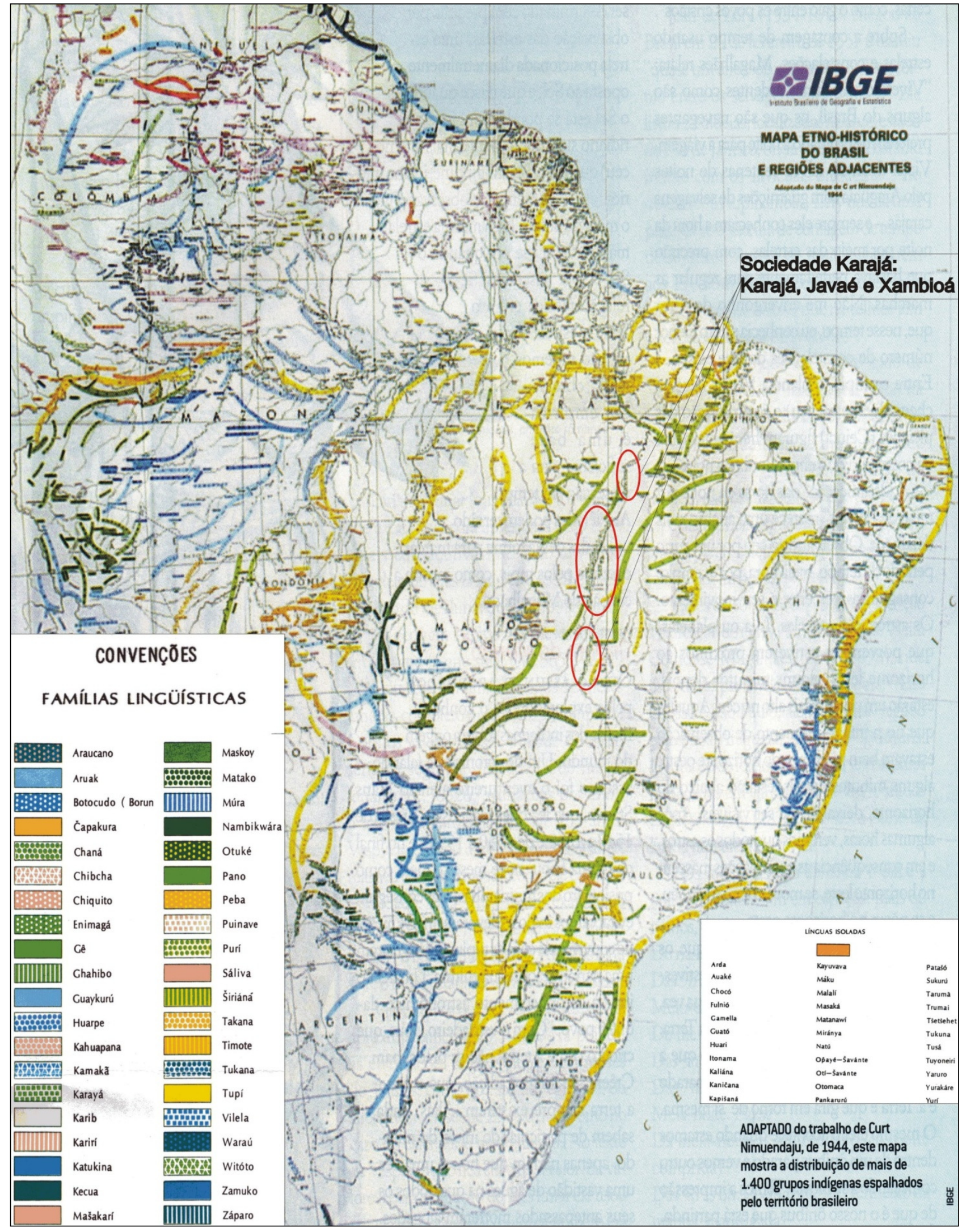

Figura 2: Distribuição etno-territorial na terra brasilis e vizinhança, desde o início do século XVI, com destaque para a Família Karajá.

Fonte: IBGE, 2002. Adaptado de Curt Nimuendaju, 1944. Reduzido por Lima (2006), In: Etnoastronomia, Scientific American. Readaptado e Organizado por: Loiola, S. A., 2007. 
"Vivendo em climas ardentes como são alguns do Brasil, os que são navegantes preferem de ordinário a noite para a viagem. Viajei dezenas, talvez centenas de noites pelo Araguaia com guarnições de selvagens carajás - e sempre eles conheciam a hora da noite por meio de estrelas, com precisão que bastava perfeitamente para regular as marchas. Não me envergonho de dizer que, nesse tempo, eu conhecia muito menor número de constelações do que eles. [...] Entre os tupis, o planeta Vênus (que se chama laci-tatá-uaçu) e a constelação das plêiades (Ceiuci) figuram frequentemente na contagem do tempo durante a noite." (apud LIMA FILHO, 2006: 83)

Referindo-se as riquezas dos karajá xambioá, em 1844 o naturalista francês Castelnau se encantou com a capacidade deles produzirem artesanatos, tecidos e alimentos:

[...] muito industriosos, pois fazem grandes plantações, como prova a grande quantidade de bananas e legumes com que a expedição foi presenteada. Eles também cultivam o algodão, cuja fibra as mulheres fiam e tecem para fazer cordas e redes. (CASTELNAU, 1844, apud DOLES e NUNES, 1992: 110)

Assim como os demais povos autóctones no Brasil, a mitologia karajá é rica em marcadores espaço-temporais convertidos em memórias socioambientais. São portadores de ricos rituais míticos, cujas narrativas fazem referencias simultâneas ao espaço e o tempo (FIGURA 3).

Tão importante quanto terminologias e conceitos é rever trajetórias e aspectos mitológicos a fim de ampliar a noção sobre as civilizações milenares na América. Sua trajetória e mitos são partes da memória e trazem signos de sua história. Os Karajá estão entre as sociedades que compõe essas civilizações. Sua autodenominação é Inÿ ou nós. Entretanto, são mais conhecidos como Karajá, palavra de origem tupi-guarani cujo significado é macaco grande, certamente atribuída por outras etnias (TORAL, 1992).

É provável que os ancestrais dos Karajá, ou proto-Karajá, da Fase Aruanã e Tradição Uru, tenham migrado de culturas amazônicas antes de 1500, seguindo a planície do Rio Araguaia e ocupado a porção meridional da Ilha do Bananal, mas há muito tempo se diferenciaram das origens (WUST, 2001, 1994, 1984; TORAL, 1992). Situados há mais de cinco séculos na planície do Rio Araguaia ou Berohokã, água grande na língua Karajá, é possível que tiveram sua etnogênese na planície desse Rio (LIMA FILHO, 1999).

A sociedade Karajá, é composta por três sub-grupos de história de vida, cultura e língua em comum: Javaé, povo do meio (Ilha do Bananal), Xambioá, povo de baixo (Estado do Tocantins), e Karajá, povo de cima (cidade de Aruanã). Para o Lingüista Ayron Dall'Igna Rodrigues (1986) esses grupos integram a família lingüística Karajá, pertencente ao Tronco lingüístico Macro-Jê, tronco provavelmente originário da Amazônia (FIGURA 4). 


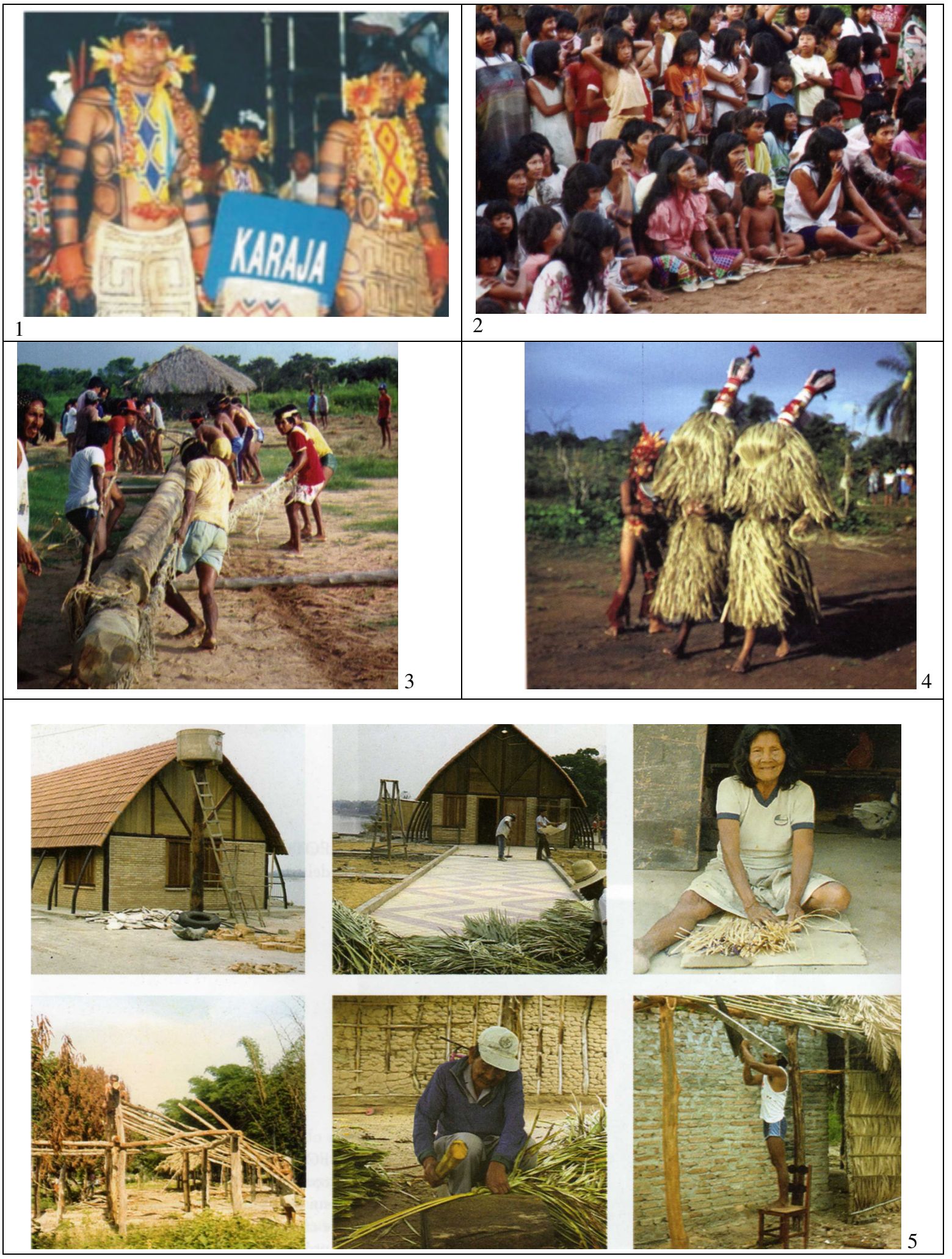

Figura 3: Sociedade Karajá: 1-Hetohoky, 2- assistindo ritual, 3-puxada de mastro, 4- festa do Aruanã na llha do Bananal e 5-Atividades cotidianas na Aldeia Buridina, Aruanã, Goiás.

Fonte: Foto 1: Daniel Farias, FUNAI, 2002.; foto 2, 3 e 4: Lima Filho, 1990; foto 5: IGPA, $2006^{10}$ Elaboração: Loiola, 2007.

\footnotetext{
${ }^{10}$ In: Acervo de Imagens do IGPA, Nunes e Barbosa (2006).
} 


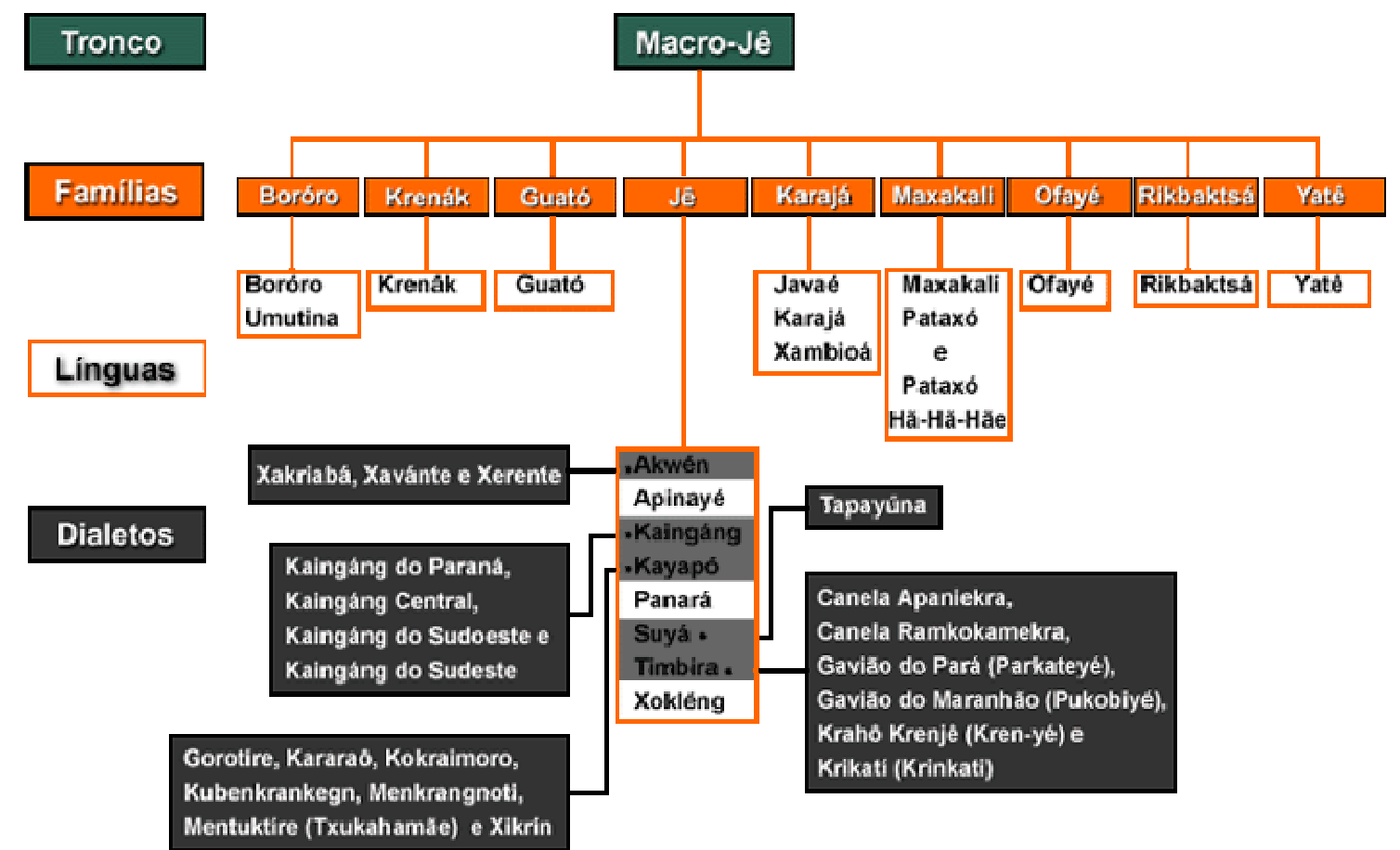

Figura 4: Famílias lingüísticas do tronco Macro-Jê, incluindo os Javaé, Karajá e Xambioá.

Fonte: Classificação do Prof. Ayron Dall'Igna Rodrigues, $1997 .^{11}$

A narrativa mítica karajá une passado e futuro, não contendo início nem fim determinado, mas permite identificar uma perspectiva topoetnica, fazer alusão a espaços de referências. As cheias e vazantes do rio Araguaia fazem parte da estruturação dos seus mitos e dos ciclos de subsistência: plantio, pesca e coleta, bem como os ritmos da estrutura social, o papel dos gêneros, o casamento, o xamanismo, o poder político, a gênese, as doenças, o parentesco, o tempo do contato com o branco e a morte (LIMA FILHO, 2006: 148). Esses mitos fundadores têm proximidades com os de outros povos.

Para RODRIGUES (2004: 14), a formação social dos javaê, da família karajá, originou-se de grupos jê-Bororo, aruak, tupi em menor grau e atualmente integra alguns aspectos tecnológicos ocidentais. Suas matrizes mitológicas encontram duas similitudes básicas entre esses povos. Uma relacionada ao povo wèrè, que teria surgido a leste da ilha do Bananal, do fundo das águas, cujas características são encontradas junto aos jê-bororo e povos do Brasil Central, e outra referente ao Tòlòra, encontrados no Alto Xingu.

Lima Filho (1991), Toral (1992), Rodrigues $(2004,1993)$ e Simões (1992) identificaram essa estreita relação da cosmologia karajá com o rio Araguaia. Seus mitos estão fundamentados em representações imaginativas da planície ribeirinha do Araguaia.

\footnotetext{
${ }^{11}$ Disponível em: www.isa.org.br Acessado em: 4/2006.
} 
As espécies animais, o regime sazonal do Araguaia, o clima, as estrelas, o Sol, a Lua, a flora, sua sociedade e cultura material coadunam-se numa paisagem. Esta, representada nos mitos e transmitida nos ritos, tornou-se matriz da sua reprodução cultural. Assim como Heródoto descreveu a importância do rio Nilo para a civilização egípcia, por analogia os karajá são uma "dádiva do Araguaia".

A centralidade do rio Araguaia na vida dos karajá se dá de variadas formas: é referencial de localização, marcador temporal, fonte de subsistência, via de transporte, inspiração cultural e estruturação social. Associados aos ciclos sazonais de cheia e vazante desse rio, mitos e ritos orientam o período de pescar, plantar, colher, caçar, na organização, estruturação social e política (LIMA FILHO, 2006: 147-148).

Suas narrativas mitológicas expressam uma sociocosmologia e consciência de origens relacionadas ao Araguaia, transmitindo signos e valores de geração em geração por meio das danças, cantos, músicas, choros, pinturas e cerimônias rituais (RODRIGUES, 2004: 14-16). A noção de tempo, gênero, divisão de tarefas, atribuições, territorialidades, papeis sociais, a planta da aldeia e as relações sociais são orientadas por representações de uma geografia imaginativa, referenciados no Araguaia.

Na cosmologia javaé, ou karajá do meio, grupo da família karajá sediado na Ilha do Bananal, de acordo com RODRIGUES (2004: 20), não há oposição entre o microcosmo das pinturas corporais e o macrocosmo das aldeias dos vivos e dos mortos. Um centro mediador une extremos dos processos universais, não havendo limites definidos entre conceitos aparentemente opostos. O mundo é estabelecido na relação entre os seres que o povoam, numa eterna transformação relacional, no qual os indivíduos estão ligados por um só corpo. Desse modo, RODRIGUES (2004: 24) descreve que na teoria social javaé, estar no mundo se constitui um processo relacional, criativo e transformador resultante da interação de três mundos interativos. Um é subaquático, onde mora o Berahatxi Mahãdu, povo do fundo das águas. O segundo mundo é o celeste. Lá mora o Povo do Céu, Aruanãs xamãs, heróis criadores e transformadores cósmicos. Esses dois mundos seriam anteriores à ascensão ao plano terrestre.

O lugar dos Aruanãs, o subaquático, é habitado por seres mágicos, mascarados e imortais, de onde certa vez um jovem corajoso, interessado em conhecer a superfície, encontrou uma passagem e as belezas e riquezas do Araguaia; encantado, convidou outros do fundo das águas para viver na superfície. Após encontrar doenças e mortes tentaram retornar ao fundo 
do Araguaia e à imortalidade, porém, o chefe das águas ordenou a grande cobra (Koboi) para fechar a passagem. Desde então, teriam sido "aprisionados" nas planícies do rio Araguaia, vivendo como uma dádiva do Araguaia.

O ritual anual dos Aruanãs representa a tentativa dos homens de recriar a imortalidade perdida quando da passagem para o mundo da superfície. A um só tempo, as danças rituais do Aruanã funcionam como calendário hidrológico, pois coincidem com o início e o final da estação chuvosa, período bom para pesca, plantio e colheita.

Durante a dança dos Aruanãs, no ponto alto da festa, ocorre o ritual do Hetohokÿ (Casa Grande), cerimônia que simboliza o rito de passagem dos jovens masculinos à fase adulta. Os homens são divididos em homens de cima, do meio e de baixo, conforme o mito de sua formação e a própria estruturação geográfica das aldeias e subgrupos étnicos ao longo do Araguaia.

\section{Dimensão espacial na Mitologia Karajá}

Há assim uma correspondência entre a simbologia do mito de criação e a distribuição espacial dos grupos da família karajá, de aldeias, casas de moradias, casas rituais e cemitérios (LIMA FILHO, 2006: 148). O rio Araguaia é o eixo de referência dessa distribuição. A ocupação do Araguaia à montante e à jusante, a partir da llha do Bananal, correlaciona-se com a cosmologia karajá, a partir do momento mitológico em que teriam sido aprisionados na superfície desse rio. Aqueles que teriam migrado ao norte da llha do Bananal originaram os xambioá, ou Povo de Baixo (Iraru Mahãdu). Aqueles que foram para o lado sul dessa Ilha fizeram surgir os Karajá ou Povo de cima (Ibóó Mahadu). Os javaé, que se concentraram na Ilha do Bananal e entorno, configuraram o Povo do meio (Itua Mahãdu).

Esta estruturação cosmológica nos mitos perpassa a orientação da planta das aldeias. Nas aldeias as casas são dispostas em duas retas paralelas e são divididas em três segmentos simétricos ao longo dessas retas: as casas de cima, do meio e de baixo (LIMA FILHO, 2006: 148). As casas rituais seguem essa mesma organização: a casa pequena rio abaixo, a casa grande rio acima e a Casa do Aruanã situa-se entre ambas.

Os karajá foram capazes de tomar emprestadas técnicas e valores da cultura ocidental sem perder os signos culturais, míticos, cosmológicos e a língua que os diferencia etnicamente (RODRIGUES, 2004: 23). Os karajá seguem realizando a festa do Aruanã, homenagem a um 
peixe do Araguaia que acreditam proteger a comunidade (LIMA FILHO, 2006: 148). O rio Araguaia se mantém como eixo central de sua estruturação social, inspiração cultural, meio de transporte, referencial de localização, marcador temporal e fonte de subsistência.

A pesca continua a ser uma das principais fontes de proteína, e os karajá fazem seus tradicionais acampamentos sazonais junto ao Araguaia. É possível que a tradição goiana de acampar e realizar pescarias com a família às margens desse rio durante o mês de julho seja uma assimilação cultural da tradição karajá .

Esses são os signos de uma cultura milenar viva, dinâmica no tempo e permeável, cuja trajetória descreve marcadores espaço-temporais, signos de suas memórias socioambientais. "Não se deve acreditar que a sociedade urbana seja a única merecedora de estudos, mesmo porque ela não é mais do que uma das escolhas possíveis dos grupos humanos" (PROUS, 1992, p. 1)

\section{CONCLUSÕES}

Heranças na paisagem, na memória, nas informações e na cultura material são elementos da multidimensionalidade do espaço-tempo socioambiental, agindo como substrato e condição à sua realização. Não o determinam, mas interagem, ampliando o leque de possibilidades à materialização de novas realidades.

Perceber a interação dos resíduos do passado na realização do espaço-tempo socioambiental requer olhares que ultrapassem as estruturas, formas e as ações presentes, já que requer abranger diferentes níveis de realidade. Ver além das formas herdadas é buscar significados nos elementos imateriais e sondagens indiretas, igualmente portadores de argumentos potenciais de memórias socioambientais.

Nesse processo de interação entre signos do passado e o acontecer presente, intermediados por escolhas socioculturais, regularidades celestiais, ciclos ambientais e ritmos sociais são convertidos em marcadores espaço-temporais. Resultantes de um acúmulo diferencial contínuo de aprendizagem e saberes, os marcadores evidenciam a indissociabilidade socioambiental e espaço-temporal do holomovimento criativo da natureza. São expressões de potencialidades manifestas, impossíveis de serem apreendidas fora de suas teias de relações presentes e herdadas. 
O uso dos marcadores espaço-temporais ocorre há dezenas de milhares de anos nas mais distintas sociedades, seja imersos em movimento celestiais, fenômenos climáticos, ciclos diuturnos, biológicos ou aspectos socioculturais. Tal esforço exige o desenvolvimento de sofisticadas técnicas de mensuração, sensibilidade e habilidades para observar, construir objetos e utilizar o conhecimento na estruturação social.

Se por um lado o uso de marcadores espaço-temporais é inerente às sociedades, por outro, sua adoção não é uniforme. Suas escolhas são orientadas por padrões culturais e demandas ambientais, assumindo variadas formas. É difícil a tarefa de observar a profusão de noções de tempo e espaço em outras sociedades, pois os padrões conceituais sobre o tempo e espaço na civilização ocidental estão tão arraigados que impedem conceber como outros povos viveram e vivem sem o tempo cronológico, o relógio e a geometria euclidiana.

Inseridos nessa diversidade de modos de marcação estão às sociedades autóctones no Brasil, uma civilização oculta, cuja base funda-se na observação de marés, ciclo anual dos rios e plantas, períodos de estiagem, chuvas, frutificação, observações do firmamento, rituais e mitos.

Assim, sob representações imaginativas ou formais, cartográficas ou mentais, cronológicas, rituais ou mitológicas, intermediadas por escolhas, marcadores espaço-temporais e todo tipo de formas e signos herdados ou atribuídos orientam ações atuais, convertendo-se em atributos de memórias socioambientais, a partir do colapso de eventos e escolhas dentre um leque de infinitas possibilidades, potencialmente manifestas no holomovimento ininterrupto do espaço-tempo socioambiental.

Enviado para AValiação em Nove de Julho de 2009.

\section{REFERÊNCIA BIBLIOGRÁFICA}

AFONSO, Germano. (2006) Mitos e estações no céu tupi-guarani. In: Scientific American.

Edição especial: Etnoastronomia, n. 14, p. 46-55. s/d.

ALBUQUERQUE, Veleda Lucena. (1989) Participação da geografia na interpretação arqueológica. 217 f. Dissertação (Mestrado em geografia) - Faculdade de Ciências da Terra. Universidade Federal de Pernambuco. 
ARAÚJO, Adauto Araújo e FERREIRA, Luiz Fernando. Homens e parasitos: a contribuição da paleoparasitologia para a questão da origem do homem na América. In: Revista USP, Dossiê Surgimento do Homem na América, n. 34, junho/agosto, 1997, p. 58-69.

BERQUE, Augustin. Paisagem marca, paisagem matriz: elementos da problemática para uma geografia cultural. 2. In: ROSENDAHL, Zeni; CORRÊA, Roberto Lobato (Org.). Paisagem, tempo e cultura. Rio de Janeiro: Ed. UERJ, 2004. p. 84- 91.

BORGES, Luiz Carlos. (2006) Evolução do registro de tempo. In: Scientific American. Edição especial: Etnoastronomia, n. 14, p. 38-45. s/d.

CLAVAL, Paul. As abordagens da geografia cultural. In: CASTRO, Iná Elias de; GOMES, Paulo César da Costa; CORREA, Roberto Lobato (Org.). Explorações Geográficas: percursos no fim do século. Rio de Janeiro: Bertrand Brasil, 1997. p. 89-118.

COSGROVE, Denis. A geografia está em toda parte: Cultura e simbolismo nas paisagens humanas. In: CORRÊA, Roberto Lobato \& ROZENDAHL, Zeny (Org.). Paisagem, Tempo e Cultura. Rio de Janeiro: EDUERJ, 1998. p.92-123.

DOLES, Dalísia Elisabeth M; NUNES, Heliane Prudente. (1992) Memória da ocupação e colonização de Goiás na primeira metade do século XIX: A visão dos viajantes europeus. In: Ciências humanas em Revista. Goiânia, v.3, n.1/2, p. 71-118.

ELIAS, Norbert. Sobre o tempo. Rio de Janeiro: Jorge Zahar, 1998. 165 p.

FABIAN, Stephen M. (2006) Astrônomos do Cerrado. In: Scientific American. Edição especial: Etnoastronomia, n. 14, p. 56-61. s/d.

FOGAÇA, Emilio; BOEDA, Eric. (2006) A antropologia das técnicas e o povoamento da América do Sul pré-histórica. Habitus, v. 4, p. 673-684. 
FREITAS, Inês Aguiar. História Ambiental e Geografia cultural: natureza e cultura com chaves para o entendimento do nosso tempo. In: ENCONTRO DA COMISSÃO SOBRE O ENFOQUE CULTURAL NA GEOGRAFIA - UNIÃO GEOGRÁFICA INTERNACIONAL. Anais, Rio de Janeiro, UERJ, 2003. 1 CD ROM.

FUNARI, Pedro Paulo A. e NOELLI, Francisco Silva. Pré-História do Brasil. São Paulo: Contexto, 2002.

GOMES, Paulo César da Costa. (1998) Identidade e exílio: fundamentos para a compreensão da cultura. Espaço e cultura, Rio de Janeiro, no 5, p. 31-41, jun./jul.

GOSWAMI, Amit. O universo autoconsciente: como a consciência cria o mundo material. Tradução: Ruy Jungmann. 4 ed. Rio de Janeiro: Rosa dos Tempos, 2001, 357 p.

GUIDON, Niéde. (2004) Serra da Capivara: 50 mil anos de presença humana. História viva, São Paulo, Duetto, ano 1, n. 10, ago. p. 74-81.

KRENAK, Ailton. Antes, o mundo não existia. In: NOVAES, Adalto (Org.). Tempo e História. São Paulo: Companhia das Letras, 1992. p. 201-204.

LIMA FILHO, Manuel Ferreira. Karajá de Aruanã. In: MOURA, Marlene Castro Ossami de (Org.). Índios de Goiás: uma perspectiva histórico-cultural. Goiânia: Ed. da UCG/ Ed. Vieira/ Ed. Kelps, 2006. p.135-152.

LOIOLA, Sérgio Almeida. (2008) Por uma geografia do passado distante. Marcas pretéritas na paisagem como memória espacial das sociedades autóctones. 180 f. Dissertação (Mestrado em Geografia) - Instituto de Estudos Socioambientais, Universidade Federal de Goiás, Goiânia.

. Por uma geografia do passado distante. (2007) Marcas pretéritas na paisagem como memória socioespacial das sociedades autóctones. Terra Livre. A Geografia no tempo de Novos Conhecimentos do Espaço. AGB, Ano 23, v.2, n.29, p. 265-296, ago./dez. 
. LOIOLA, Sérgio Almeida. (2010) Do espaço e tempo ao espaço-tempo: dimensões e marcas. Geografia, Associação de Geografia Teorética - AGETEO, Rio Claro, Vol. 35, n. 1, p. 5-20, jan,/abr.

MASSEY, Doreen. (1999) Space-time, 'science' and the relationship between physical geography and human geography. Transactions of the Institute of British Geographers, v. 24, n. 3, set., p. 261-276.

MORIN, Edgard \& LE MOIGNE, Jean-Lois. A inteligência da complexidade. São Paulo: Peirópolis, 2000. 263 p.

PROUS, André. O Brasil antes dos brasileiros: a pré-história de nosso país. Rio de janeiro: Jorge Zahar, 2006.

Definição e histórico da arqueologia. In: TENÓRIO, Maria Cristina (Org.).

Pré-

história da terra brasilis. Rio de Janeiro: Editora da UFRJ, 1999. p. 19 - 34.

RODRIGUES, Patrícia de Mendonça. (2004) O povo do meio: uma paradoxal mistura pura. Revista de Estudos e Pesquisas, FUNAI, Brasília, v.1, n.1, jul., p.11-63,

. (1993) O povo do meio - tempo, cosmo e gênero entre os Javaé da llha do Bananal. 438 p. Dissertação (Mestrado em Antropologia). Departamento de Antropologia. Universidade de Brasília.

SANTOS, Milton. Da sociedade à paisagem: O significado do espaço do homem. In: SANTOS, Milton. Pensando o espaço do homem. São Paulo: EDUSP, 2004, p.53- 62. . Metamorfose do espaço habitado. São Paulo: Hucitec, 1997. 124 p. . A natureza do espaço: Técnica e tempo. Razão e Emoção. São Paulo: Hucitec, 1996. 307 p. 
. Sociedade e Espaço: a formação social como teoria e método. In: SANTOS, Milton. Espaço e sociedade. Petrópolis: Vozes, 1979. 156 p.

SEEMANN, Jörn. Mapeando culturas e espaços: uma revisão para a geografia cultural no Brasil. In: ALMEIDA, Maria G; RATTS, Alecsandro José Prudêncio (Org.). Geografia: leituras culturais. Goiânia: Alternativa, 2003. p. 261-284.

SIMÕES, Mário Ferreira. Cerâmica Karajá e outras notas etnográficas. Goiânia: Editora da UCG/IGPA, 1992.

TENÓRIO, Maria Cristina. Coleta e processamento e início da domesticação de plantas no Brasil. In: TENÓRIO, Maria Cristina (Org.). Pré-história da Terra brasilis. Rio de Janeiro: Editora da UFRJ, 1999. p. 259-271.

TORAL, André Amaral de. (1992) Cosmologia e Sociedade Karajá. 414 p. Dissertação (Mestrado em antropologia) - Universidade Federal do Rio de Janeiro.

WORSTER, Donald. (1991) Para fazer História Ambiental. Estudos Históricos, v.4, n. $\quad$ 8, p.198-215. 